\title{
A Phenomenal Conservatist Response to Tradition-Based Perspectivalism
}

\section{Logan Paul Gage and Blake McAllister}

MacIntyrean metaepistemology, as Baldwin presents it, is a secondorder (or meta-level) reflection of our epistemic practices, standards, and systems. As such, it is related but also orthogonal to first-order theories of warrant and justification such as Phenomenal Conservatism (PC), Proper Functionalism, and Classical Evidentialism. Thus, the MacIntyrean approach is not necessarily an alternative to these first-order theories. ${ }^{1}$ In what follows, we aim to show how PC incorporates many of the insights of MacIntyrean metaepistemology while addressing some concerns.

Notice first that there are moderate as well as extreme readings of nearly all of MacIntyre's key theses. Take Baldwin's claim that "there is no traditionindependent way to evaluate the epistemic merits of our religious beliefs and practice, no such thing as tradition-independent rationality, and no such thing as religious-epistemology-as-such that applies universally across all religious traditions." Such statements might be taken in a moderate way, claiming only that our inquiry into the rational standards governing religious belief will be heavily influenced by our various traditions and, as a result, different individuals operating in different traditions might reasonably come to different conclusions about which rational standards are correct. Or such statements can be taken in an extreme, relativistic way, claiming that there is no objective truth as to who is right about the rational standards governing our beliefs. 
Taken straightforwardly, many of Baldwin's statements strongly suggest the extreme reading. He asserts, "there is no such thing as universal rationality or theoretical-rationality-as-such, but rather that there are numerous rival tradition-based standpoints each with their own particular standards of rational justification." For comparison, what would we make of an ethicist who asserted, "there is no such thing as universal morality or morality-assuch, but rather that there are numerous rival tradition-based standpoints each with their own particular standards of morality?" We would interpret them as a moral relativist-someone who denied the existence of traditiontranscendent moral truths. At best, this would be a particularly misleading way to express the more moderate claim that, though there are objective moral truths, people coming from different traditions will often come to different conclusions about those truths.

Despite such statements, it appears to us that both MacIntyre and Baldwin proffer these theses in their more moderate senses. That is, they stress the importance of traditions in guiding our inquiries, beliefs, concepts, practices, and so on, but maintain that there are tradition-transcendent truths and that these are at least sometimes accessible to us. At times, Baldwin seems to assert this plainly: "I maintain that there are and that we can know some tradition-transcendent truths." ${ }^{2}$ He mentions in particular necessary truths, such as those of logic. We will assume, then, that Baldwin does not deny that there are universal, tradition-transcendent standards of rationality, but is merely pointing out how profoundly our investigations into such truths are guided by the tradition in which we find ourselves.

It is important to emphasize, then, that if we have correctly identified $\mathrm{PC}$ as a necessary truth about the nature of justification, then PC is such a tradition-transcendent truth. (For the record, PC states that if it seems to $\mathrm{S}$ that $p$, then $S$ thereby has some degree of justification for believing $p$, absent defeaters.) Baldwin's point is just that our ability to recognize PC as true depends on the tradition in which we are located, and that people operating in different traditions may not have the resources needed to appreciate its truth or might even be reasonable in dismissing it. We would agree with this point. ${ }^{3}$ What is reasonable to believe ultimately depends on how things seem to a person, and things may seem different to people from different traditions.

On a more general level, we also agree with Baldwin and MacIntyre that traditions and communities play a much larger role in epistemology than Enlightenment rationalists supposed. However, we do not think that this is a straightforward epistemic role, but rather largely a causal role. Many of 
Baldwin's arguments point to traditions as necessary conditions for organizing our language, concepts, and beliefs. We agree. But in what sense does this make tradition necessary? It is necessary causally, not epistemically. For example, oxygen is also necessary (in some sense) for our beliefs to be justified-for without oxygen, there would be no beliefs at all. But that is not to say that oxygen plays an epistemic role as part of what makes a belief justified or unjustified. Similarly, a community's beliefs or standards do not themselves make a belief justified or unjustified, at least not in any straightforward way. Rather, having a community of thought is a necessary causal condition for formulating your own seemings, thoughts, and beliefs, ${ }^{4}$ and it is these things that play the epistemic role in the justification of one's beliefs.

The position we are taking here is complicated, so allow us to explain it in another way. We agree that one's tradition has a profound influence on what one is justified in believing; we just want to stress that this influence is indirect-it exerts this influence by causally altering experience. The story goes like this: One's tradition affects one's conceptual frameworks, linguistic practices, and background beliefs. These affect one's experiences of the world. And how one experiences the world ultimately determines, in accordance with tradition-transcendent rational standards, what one is justified in believing. Importantly, communal beliefs and standards do not automatically become normative for an individual operating within that tradition (otherwise one would be justified in believing whatever one's community accepts, regardless of how these beliefs fit with one's own experiences).

To its credit, PC allows us to accept what is true here-namely, that our communities and traditions greatly affect our seemings and therefore what beliefs are justified for us-without accepting that the standards of rationality differ from tradition to tradition or that it is rational to accept all and only the beliefs and standards of one's own initial tradition. In this way, PC captures what is true about MacIntyrean metaepistemology while avoiding potential pitfalls.

Another big advantage of PC highlighted by Baldwin's discussion is that PC can make sense of why one is justified in accepting one's traditiondependent starting points. In order to help establish the tradition-bound nature of our epistemic starting points, Baldwin looks to Aristotle, whose philosophical methodology held that philosophy should start with the common opinions of one's community (endoxa) and attempt to clarify and elaborate upon them, only rejecting them as a last resort. ${ }^{5}$ Notice, though, that endoxa are not rock bottom. These endoxa, as Aristotle himself 
recognizes, are based upon the way things appear to people (phainomena). ${ }^{6}$ Even our communal beliefs and standards are based on the way things seem, thus confirming the claim of PC that experiences form the evidence on which our justification depends.

Lastly, we think that PC fits nicely into MacIntyre and Baldwin's tripartite schema: tradition-based perspectivalism, Enlightenment hyperrationalism (represented by the encyclopedists), and postmodern deniers of truth (such as Nietzsche). PC fits best with perspectivalism, allowing for enough objectivity to avoid postmodernism and enough subjectivity to avoid hyperrationalism. Postmodernism says, if it seems true then it is true (for that person). PC counters, if it seems true then it is reasonable to believe (for that person), but the truth of the belief remains an entirely objective matter. On the other side, PC avoids the hyperrationalist position that reasonable inquirers will all reach the exact same conclusions. PC allows for a perspectival view of rationality, where what is reasonable to believe depends on the information available from one's subjective point of view. ${ }^{7}$ Since the available information can differ greatly from subject to subject, rational inquirers can come to vastly different conclusions. In short, PC gives us the best of both worlds: it affirms objective truth and traditiontranscendent standards of rationality so as to avoid postmodernism; and it also incorporates a humane, perspectival, and even tradition-dependent account of evidence so as to avoid hyperrationalism. 